\title{
Pattern and determinants of respiratory mortality in Kerala, South India
}

\section{Sanjeev Nair, Anitha Abraham 1 , Reshmi Ramachandran', Devi Mohan ${ }^{3}$, Raman Kutty $\mathbf{V}^{4}$}

Department of Pulmonary Medicine and ${ }^{3}$ Community Medicine, Government Medical College, Thiruvananthapuram, ${ }^{1}$ Department of Community Medicine, Dr. SMCSI Medical College, Karakonam, ${ }^{4}$ Achutha Menon Centre for Health Science

Studies, Thiruvananthapuram,

${ }^{2}$ Department of Community

Medicine, Kolenchery Medical

College, Ernakulam, Kerala, India

Address for the Correspondence: Dr. Anitha Abraham,

Rajashree, TC - 27/1955(1), Thumbara Lane, GPO, Thiruvanathapuram, Kerala, India. E-mail: anitha.abr100@gmail.com

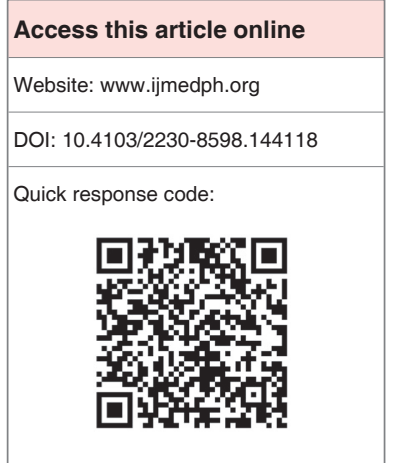

Context: Respiratory diseases are one of the leading causes of deaths world-wide. There are no published studies on the pattern and determinants of respiratory mortality from South India. Aims: The aim was to find out the pattern and determinants of respiratory mortality during July 1, 2002 to June 31, 2008 in Varkala, Thiruvananthapuram district, Kerala. Settings and Design: A nested case control study from a prospective cohort was done to find out the determinants for respiratory mortality. The main outcome measure was mortality due to respiratory causes. Materials and Methods: The data collected here are from the Population Registry of Lifestyle Diseases study, a prospective cohort study involving the long-term followup of the residents of Varkala rural development block Thiruvananthapuram district of South Kerala. Statistical analysis used: The age specific respiratory mortality rate was calculated. Chi-square test and odds ratio (OR) were measured to find out the association between exposure and outcome variables. Logistic regression was performed. Results: A total of 3467 deaths were reported among 77881 subjects above the age group of 20 years during the follow-up period. Of which $531(15.9 \%)$ were due to respiratory causes. On logistic regression smoking (AdjOR [95\% confidence interval]; 1.65 [1.25, 2.17]), lower socioeconomic status (AdjOR; 1.52 [1.24, 1.87]), lower educational status (AdJOR; 2.22 [1.15, 4.29]) and old age (>60 years) (AdjOR; 2.6 [2.03, 3.33]) were found to be the significant risk factors for respiratory mortality. Conclusion: Mortality due to respiratory causes was found to be high in Kerala, a state which has the best health indicators compared to other states in India.

Key words: Determinants, pattern, respiratory mortality, seasonal trends, smoking

\section{INTRODUCTION}

Respiratory diseases are a significant cause of mortality world-wide. The global scenario of diseases is shifting from infectious diseases to noncommunicable diseases, with chronic conditions such as heart disease, stroke and chronic obstructive pulmonary disease (COPD) now being the chief causes of death globally. ${ }^{[1]}$ However, acute respiratory infections still account for $7.1 \%$ of the deaths being the third leading cause of Mortality world-wide, whereas COPD accounts for $5.1 \%$ of total deaths world-wide being the fourth leading cause of mortality. According to WHO estimates for 2030, COPD is predicted to become the third leading cause of death. ${ }^{[2]}$

In India, as per data from Special Survey of Deaths (SSD, 2001-2003), carried out under the domain of Sample Registration System, which covered over 6,645 small areas in all the States and Union Territories, the leading cause of death in the age group above 20 years was cardiovascular disease (25\%), followed by respiratory diseases (20\%-namely COPD, asthma and tuberculosis [TB]). ${ }^{[3]}$ As per data from the Central Bureau of Health Intelligence, India deaths due to respiratory causes raised up to $17.2 \%$ in 1998 , this was $14.4 \%$ in $1993 .{ }^{[4]}$ Bronchitis, asthma, pneumonia and TB of the lungs were ranked as the leading causes of deaths in rural India. Rank-wise distribution of all diseases during 1971-991, asthma and bronchitis was a leading cause in the three decades accounting about 9-11\% of all deaths. TB was the third most killer during this time, which constitute about $5-6 \%$ of all deaths. ${ }^{[5]}$

In India, precise studies are not available to estimate respiratory health related disease burden to help proper public health interventions, to increase accountability on public health spending. Reliable data on mortality and morbidity are scarce in general; they are almost nonexistent in the rural areas of 
India. Paucity of this adequate data makes the understanding of the public health situation more complex, but one can use cause of death analysis to estimate the sickness load in the country.

Cause of death analysis (Medically certified or by Verbal autopsy) helps to identify diseases which cause high mortality and need to be prioritized. However, the data from death registration sources are neither reliable nor complete; good percent of deaths go unregistered and only $10 \%$ of deaths are medically certified.

The factors associated with increased mortality in respiratory diseases, like COPD, include the presence of co-morbidities like diabetes mellitus (DM), continued smoking, decreased physical activities, and higher age. ${ }^{[6]}$ There are several studies which show seasonal variation in respiratory diseases and morality. According to a study conducted in New Zealand, mortality from diseases of the respiratory system was most dependent on seasonal effects; with a mortality rate of $83 \%$ during the winter months. ${ }^{[7]}$ This variation is more evident in Western countries. Seasonal variation of TB has been reported from different parts of the world, although no definite and consistent pattern has been observed. The study conducted in tertiary care TB and respiratory diseases hospital in South Delhi showed the seasonality for TB, and it was found that TB cases were more in the period from April to June and less in the period from October to December. ${ }^{[8]}$

No documented evidence on state specific information for the death due to respiratory diseases in Kerala or the determinants for respiratory mortality in Kerala is available. Kerala state, with its advances in health care, is more likely to have higher proportions of deaths due to chronic respiratory diseases. Hence, this study was conducted with the aims to find out the pattern and determinants of respiratory mortality in a rural population of Varkala Block, Thiruvananthapuram district, Kerala. The transition in the health scenario now seen in Kerala is likely to be replicated in other parts of the country in the coming years.

\section{MATERIALS AND METHODS}

The data reported here are from the Population Registry of Lifestyle Diseases study, a prospective cohort study involving the long-term follow-up of the residents of Varkala rural development block Thiruvananthapuram district of South Kerala. The study was initiated by the Health Action by People (HAP), a nonprofit public health research organization. Death data collection was initiated as an integral part of the long-term follow-up of the 161942 participants enrolled in the study.

Subjects aged above 20 years of age were enrolled into an adult cohort. Separate adult questionnaires were administered to subjects who were above 20 years as of January $1^{\text {st }}$, 2002. Baseline data collection was completed on June 30, 2002. ${ }^{[9]}$ A total of 105 health workers were given thorough training in 12 sessions on survey methodology and death data collection. A pretested, structured questionnaire supported by a symptom list was provided to each health worker to help arrive at the cause of death. On almost all occasions, a reported death was investigated within 2 weeks of its occurrence by the resident health worker. All causes of death reported by the field workers were reviewed by a physician in the study center. The physician assigned a cause of death to each event on the basis of the $10^{\text {th }}$ revision of the International Classification of Diseases (ICD-10). ${ }^{[10]}$

The main outcome variable was deaths due to respiratory morbidities like asthma, breathlessness and TB. Deaths that have been determined by verbal autopsy and generally classified under respiratory deaths using ICD-10 were considered as respiratory deaths. Persons who died due to respiratory morbidities like asthma, breathlessness and TB were grouped together for analysis. In order to study the determinants of respiratory mortality, a nested case control study within the cohort mentioned above was done. The exposure variable included were socio-demographic factors like age, gender, socioeconomic status and education, behaviors like smoking and alcoholism and morbidities hypertension and DM respectively. The cases were people who died due to respiratory morbidity during the study period namely asthma, breathlessness and TB the controls were those people who died due to nonrespiratory causes during the same period.

\section{Ethical considerations}

Permission for the study was obtained from the concerned authorities, from Ethical Committee of HAP and also from the concerned local self-government authorities. Informed consent was obtained from the study participants.

\section{Statistical analysis}

Continuous variables were summarized using mean, standard deviation and categorical variables were expressed in proportion. The age specific respiratory mortality rate was calculated in events per 1000 person years. Chi-square test and odds ratio were measured to find out the association between exposure and outcome variables. Binary Logistic regression was performed using the factors found to be significant in the bivariate analysis. A significance level of $95 \%$ and an allowable error of $20 \%$ had been assumed for all these analyses. The statistical analysis had been done using SPSS version 16, IBM.

\section{RESULTS}

There were 77881 persons being followed-up in the cohort above the age of 20 years for a period of 6 years (July $1^{\text {st }}$, 2002-June $31^{\text {st }}$, 2008). Of these, during the follow-up period there were 3467 deaths due to all causes put together. Of these, 531 deaths were due to respiratory causes $(15.9 \%)$. There were 2936 deaths due to causes other than respiratory diseases. The all-cause mortality rate was $7.97 / 1000$ person years, whereas the mortality rate due to respiratory causes was $1.27 / 1000$ person years. The age specific mortality rates for all-cause mortality and mortality due to respiratory causes is given in Table 1. Proportion of respiratory deaths was found to be increasing as the age advances [Table 1]. This was more in the 
age group of above 60 years. Chi-square for trend was done to know whether the all-cause mortality shifts significantly towards respiratory mortality as the age advances, which was found to be statistically significant $(P$ value for the trend was $<0.001)$. The mean age (standard deviation) of the subjects with respiratory mortality was 72.64 (12.5) years. Whereas the mean age of subjects died due to nonrespiratory causes was found to be 65.4 years.

Table 2 shows the distribution of various socio-demographic and other determinants of respiratory and nonrespiratory deaths. Majority of respiratory deaths $(80.6 \%)$ occurred above the age of 60 years $(P<0.001)$. The proportion of deaths among males and females were comparable in both groups $(P>0.05)$. The majority of respiratory deaths occurred in subjects with lower educational status that is equal to and $<10$ years of schooling $(98 \%)$. Furthermore, respiratory mortality seemed to be high among subjects belonging to the lower socioeconomic strata $(55.34 \%)$. Proportion of smokers was high in those with respiratory mortality $(P<0.001)$. The proportion of subjects who ever consumed alcohol was high among those died due to nonrespiratory causes (16.65\%). The proportion of co-morbidities such as hypertension and DM were more among subjects with nonrespiratory mortality compared to those with respiratory mortality $(P<0.001)$.

Bivariate analysis was performed to find out the factors determining the respiratory mortality [Table 2]. The factors such as older age (above 60 years), lower educational status ( $\leq 10$ years of schooling), lower socioeconomic status (score 18 and below) and smoking were found to be significantly associated with the respiratory mortality. We didn't find any risk association with male gender, alcohol consumption and presence of co-morbidities such as diabetes and hypertension with respiratory mortality.

The final multivariate analysis, which included all the risk factors, is shown in the Table 2. On multivariate logistic regression analysis also older age, smoking, lower educational status and low economic status were found to be the significant risk factors for respiratory mortality [Table 2]. We also looked at the trends in all-cause mortality and respiratory mortality [Graph 1] and the seasonal variation in respiratory mortality [Graph 2 and Table 3]. The trend analysis shows that there is no significant change in respiratory or all-cause mortality. The Chi-square for linear trend is 1.18 ( $P$ - 0.28). There is no significant seasonal change in respiratory mortality. The maximum deaths due to respiratory causes over the 5 years occurred in the months June to August and the minimum deaths occurred in the months in the months from December to February [Table 3].

\section{DISCUSSION}

In the present study, the proportion of deaths due to respiratory causes was found to be $15.9 \%$. The statistics from various other sources also shows comparable results. According to

\begin{tabular}{|c|c|c|c|c|c|}
\hline $\begin{array}{l}\text { Age group } \\
\text { (years) }\end{array}$ & $\begin{array}{l}\text { Number of deaths } \\
\text { due to all causes }\end{array}$ & $\begin{array}{l}\text { All-cause mortality } \\
\text { rates (deaths } / 1000 \\
\text { person years) }\end{array}$ & $\begin{array}{c}\text { Number of deaths } \\
\text { due to respiratory } \\
\text { causes }\end{array}$ & $\begin{array}{l}\text { Respiratory mortality } \\
\text { rates (deaths } / 1000 \\
\text { person years) }\end{array}$ & $\begin{array}{c}\text { Proportion of deaths } \\
\text { due to respiratory } \\
\text { causes }(\%)\end{array}$ \\
\hline $20-29$ & 119 & 1.02 & 6 & 0.06 & 5 \\
\hline $30-39$ & 193 & 2.05 & 10 & 0.10 & 5.2 \\
\hline $40-49$ & 289 & 4.41 & 16 & 0.28 & 5.5 \\
\hline $50-59$ & 471 & 10.21 & 39 & 1.21 & 8.3 \\
\hline $60-70$ & 977 & 25.95 & 152 & 4.50 & 15.6 \\
\hline $70-80$ & 888 & 49.95 & 185 & 10.48 & 20.8 \\
\hline $80-90$ & 454 & 82.73 & 107 & 22.66 & 23.6 \\
\hline $90-100$ & 73 & 122.12 & 15 & 17.04 & 20.5 \\
\hline 100 and above & 3 & 133.02 & 1 & 133.02 & 33.3 \\
\hline
\end{tabular}

\begin{tabular}{|c|c|c|c|c|c|}
\hline \multirow[t]{2}{*}{ Variables } & \multirow{2}{*}{$\begin{array}{c}\text { Death due to } \\
\text { respiratory cause } \\
n(\%)\end{array}$} & \multirow{2}{*}{$\begin{array}{l}\text { Death due to } \\
\text { nonrespiratory } \\
\text { cause } n(\%)\end{array}$} & \multicolumn{2}{|c|}{ Bivariate analysis } & \multirow{2}{*}{$\begin{array}{c}\text { Multivariate analysis } \\
\text { Adjusted OR } \\
(95 \% \mathrm{Cl})\end{array}$} \\
\hline & & & $P$ & OR $(95 \% \mathrm{Cl})$ & \\
\hline Age group: $>60$ years & $428(80.6)$ & $1173(60.4)$ & $<0.001$ & $2.73(2.17-3.42)$ & $2.6(2.03-3.33)$ \\
\hline Male: Gender & $304(57.3)$ & $1622(55.2)$ & 0.39 & $1.08(0.09-1.31)$ & * \\
\hline Education: $<10$ years of schooling & $478(98)$ & $2591(93.2)$ & $<0.001$ & $3.5(1.84-6.6)$ & $2.22(1.15-4.29)$ \\
\hline $\begin{array}{l}\text { Socioeconomic status: Low score } \\
\text { (18 and below) }\end{array}$ & $290(55.34)$ & $1233(42.84)$ & $<0.001$ & $1.65(1.37-1.99)$ & $1.52(1.24-1.87)$ \\
\hline Ever smoked & $223(42)$ & $1012(34.5)$ & 0.001 & $1.37(1.14-1.66)$ & $1.65(1.25-2.17)$ \\
\hline Diabetes & $79(14.9)$ & $680(23.2)$ & $<0.001$ & $0.058(0.45-0.74)$ & $0.69(0.53-0.93)$ \\
\hline Alcoholism & $53(9.98)$ & $489(16.65)$ & $<0.001$ & $0.55(0.41-0.75)$ & $0.506(0.36-0.71)$ \\
\hline Hypertension & $116(21.8)$ & $798(27.2)$ & $<0.001$ & 0.036 & $0.79(0.64-0.94)$ \\
\hline
\end{tabular}

*Only those variables with $P<0.05$ on bivariate analysis was taken for multivariate analysis, $\mathrm{OR}=\mathrm{Odds}$ ratio, $\mathrm{Cl}=\mathrm{Confidence} \mathrm{interval}$ 


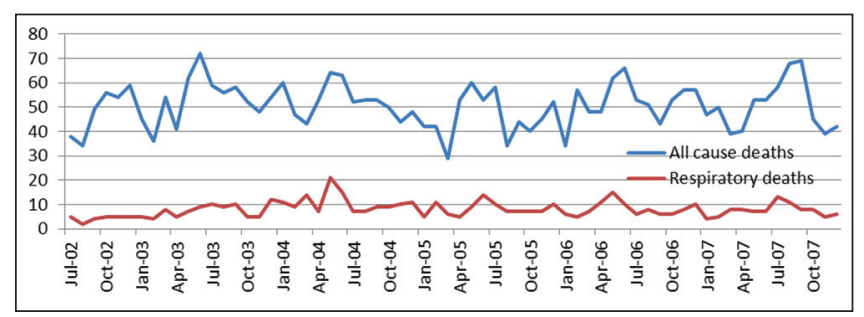

Graph 1: Trends in all cause and respiratory mortality

\begin{tabular}{|c|c|c|c|c|}
\hline Cause of death & $\begin{array}{c}\text { December } \\
\text { to } \\
\text { February }\end{array}$ & $\begin{array}{l}\text { March } \\
\text { to May }\end{array}$ & $\begin{array}{l}\text { June to } \\
\text { August }\end{array}$ & $\begin{array}{c}\text { September } \\
\text { to } \\
\text { November }\end{array}$ \\
\hline All (\%) & $714(23.6)$ & $680(22)$ & $888(29.3)$ & $740(24.5)$ \\
\hline Respiratory (\%) & $115(22.7)$ & $138(27.2)$ & $143(28.3)$ & $110(21.7)$ \\
\hline
\end{tabular}

SSD, undertaken in India (2001-2003) the proportion of deaths contributed by respiratory deaths in the age group above 20 years was around 20.3\% $\%{ }^{[3]}$ Among which COPD and asthma contributes to $10.2 \%$ and among the communicable diseases TB contributes to $10.1 \%$. The Center Bureau of Health Intelligence 1998 data also shows that in India deaths due to respiratory causes accounted for $17.2 \%$ of deaths. ${ }^{[4]}$ This study also shows a similar pattern and that respiratory diseases are a major cause of mortality even in a rural community.

One of the limitations of the study is that the cause of death has been determined by verbal autopsy and has been generally classified as respiratory deaths and does not give disease specific cause of death so that death from individual diseases like COPD, Pneumonia, etc., cannot be made out separately. However, this is one of the few population based studies from a rural area in India reporting cause specific mortality and age specific mortality for respiratory causes. Hence, the study has important policy implications for Kerala and India. Some of these are discussed below.

Mortality due to respiratory causes was found to be increasing as age advances; the Chi-square for trend was $<0.001$ [Table 1]. In this study, we can see that in older age group ( $>60$ years), the higher proportion of deaths occurred due to respiratory causes rather than nonrespiratory causes of deaths. It may be because the common respiratory causes of mortality include COPD, which occurs only after 40 years of age and is a slowly progressing disease, causing mortality in older populations. Furthermore, diseases like TB and pneumonia are more fatal when they occur in older populations. Many studies show that males die early due to chronic respiratory disease such as COPD. In this study, the deaths among males were comparable in both the groups. Hence, we didn't find any association between male gender and respiratory mortality.

In the present study, both low education and low socioeconomic status were observed to be an important risk factor for respiratory mortality. A risk factor study conducted in China also shows

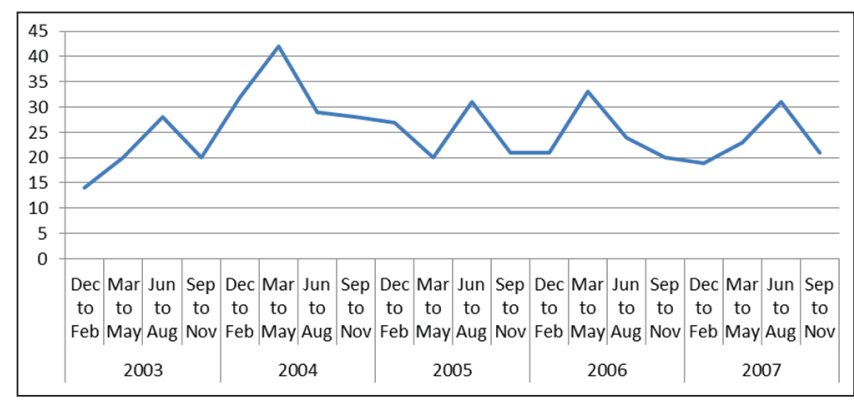

Graph 2: Seasonal trends in respiratory mortality

similar results. ${ }^{[6]}$ In a study conducted in different states of India, low socioeconomic status was found to be an important factor for COPD. ${ }^{[11]}$

Our study found that the respiratory mortality was high among those ever smoked compared to those who never smoked in their life. The above mentioned study from China also shows that cigarette smoking is an important risk factor for COPD mortality. ${ }^{[6]}$ Another study on trends of mortality in Washington found that chronic respiratory deaths were found to be more among subjects who were smokers at the beginning of the survey. ${ }^{[12]}$ COPD, which is a common cause of respiratory mortality, is a relentlessly progressive disease and the only management options which offer a survival benefit to COPD patients are smoking cessation and long-term oxygen therapy (LTOT). LTOT is too costly for people living in the developing countries; hence prevention through tobacco control is a more cost effective intervention to help people live longer.

In this study alcohol, consumption among men was found to be a significant protective factor for respiratory disease related mortality. Study conducted in China also got similar results and found that alcohol consumption was protective for men with COPD related mortality. ${ }^{[6]}$ Another study done in three European countries also shows that those who consume a moderate amount had a low risk for COPD mortality compared with nondrinkers and heavy drinkers. ${ }^{[13]}$

Most studies on COPD and Asthma in the world report higher mortality during winter. However, most of these studies come from European countries, countries like USA and New Zealand. ${ }^{[7]}$ There is no data from tropical countries which have milder winters on the seasonal mortality in respiratory diseases. This study shows that there are no seasonal differences in respiratory mortality in Kerala. In fact, the number of respiratory mortality is higher in the months March to August as compared to the winter months of December to February. This can be explained by the fact that with a tropical climate in Kerala, the winters are mild. The monsoon and summer seasons are often associated with outbreaks of fever epidemics, and this may also cause infective exacerbations of COPD resulting in higher mortality due to respiratory causes in these months. This finding should lead to a rethink in tropical countries on the accepted belief of higher 
mortality in winter leading on to planning specific interventions during the winter months.

In the scenario of noncommunicable diseases accounting for a higher proportion of mortality in India, the government of India has launched a national program for noncommunicable diseases, National Program for Prevention and Control of Diabetes, Cardiovascular Disease and Stroke. However, this program addresses only diabetes, cardiovascular diseases and stroke. The lack of data in India on how much respiratory diseases contribute to mortality and morbidity has resulted in the fourth leading cause of mortality in the world, COPD, being left out from this national program. Early identification of COPD and smoking cessation as an intervention would have resulted in reducing the mortality due to respiratory causes.

The state of Kerala has an aging population with an increasing trend of population in older age groups; above 60 year population $(11.6 \%) \cdot{ }^{[14]}$ Life expectancy at birth in Kerala is 74 years higher compared to that in India 63.5 years. ${ }^{[15]}$ As off now there is no wellstructured geriatric health service in India as well as in Kerala. The care is being given mainly financial by means of social assistance, old age pension schemes, etc. Hence, the government of the state of Kerala is now planning to develop strategies and medical education programs for geriatric care. The fact that increasing proportions of patients in the older age groups die of respiratory causes would suggest that the government of Kerala should prioritize care of respiratory diseases in its geriatric care program.

\section{REFERENCES}

1. World Health Statistics 2008. WHO Publication 2008. Available from: http://www.who.int/whosis/whostat/EN_WHS08_Full.pdf. [Last accessed on 2013 Oct 23].

2. Acute Respiratory Infections Atlas. World Lung Foundation Publication, 2010. Available from: http://www.ariatlas.org/tools/downloads/files/ARIA. pdf. [Last accessed on 2012 Nov 10].

3. Summary-Report on Causes of Death: 2001-03 in India. Report on Causes of Death: 2001-03, Office of Registrar General, India. Page 2. Available from: http://www.censusindia.gov.in/Vital_Statistics/Summary_ Report_Death_01_03.pdf. [Last accessed on 2013 Aug 25].
4. Cause of Death Statistics 2005. Total Number and Percentage of Deaths by Major Cause Groups in India (rural). 1993-1998. Central Bureau of Health Intelligence. Available from: http://www.cbhidghs.nic.in/. [Last accessed on 2012 Feb 14].

5. Ramanakumar AV, Aparajita C. Respiratory disease burden in rural India: A review from multiple data sources. Internet J Epidemiol 2005;2.

6. Reilly $\mathrm{KH}, \mathrm{Gu} \mathrm{D}$, Duan X, Wu X, Chen $\mathrm{CH}$, Huang J, et al. Risk factors for chronic obstructive pulmonary disease mortality in Chinese adults. Am J Epidemiol 2008;167:998-1004.

7. Davie GS, Baker MG, Hales S, Carlin JB. Trends and determinants of excess winter mortality in New Zealand: 1980 to 2000. BMC Public Health 2007;7:263.

8. Behera D, Sharma PP. A retrospective study of seasonal variation in the number of cases diagnosed at a tertiary care tuberculosis hospital. Indian J Chest Dis Allied Sci 2011;53:145-52.

9. Soman CR, Shahulhameed S, Ramankutty V, Vijayakumar K, Kunjukrishnapillai R, Ajayan K, et al. Cohort profile: The PROLIFE study in Kerala, India. Int J Epidemiol 2011;40:10-4.

10. World Health Organization. ICD-10: International Statistical Classification of Diseases and Related Health Problems: Tenth Revision. $2^{\text {nd }}$ ed Geneva, Switzerland: World Health Organization; 2004.

11. Jindal SK, Aggarwal AN, Chaudhry K, Chhabra SK, D'Souza GA, Gupta D, et al. For Asthma Epidemiology Study Group. A multicentric study on epidemiology of chronic obstructive pulmonary disease and its relationship with tobacco smoking and environmental tobacco smoke exposure. Indian J Chest Dis Allied Sci 2006;48:23-9.

12. Tockman MS, Comstock GW. Respiratory risk factors and mortality: Longitudinal studies in Washington County, Maryland. Am Rev Respir Dis 1989;140:S56-63

13. Tabak C, Smit HA, Räsänen L, Fidanza F, Menotti A, Nissinen A, et al. Alcohol consumption in relation to 20-year COPD mortality and pulmonary function in middle-aged men from three European countries. Epidemiology 2001;12:239-45.

14. International Institute for Population Sciences (IIPS) and Macro International. National Family Health Survey (NFHS-3), 2005-06: Kerala. Available from: http://www.hetv.org/india/nfhs/nfhs3/NFHS-3-Keralastate-report.pdf. [Last accessed on 2013 Oct 12].

15. Annual Report to the People on Health, Govt. of India Ministry of Health \& Family Welfare. Chapter II. 2010. p. 4. Available from: http://www.mohfw. nic.in/WriteReadData//892s/9457038092Annual Reporthealth.pdf. [Last accessed on 2013 Oct 12].

How to cite this article: Nair S, Abraham A, Ramachandran R, Mohan D, Kutty RV. Pattern and determinants of respiratory mortality in Kerala, South India. Int J Med Public Health 2014;4:467-71.

Source of Support: Nil, Conflict of Interest: None declared. 